\title{
Analysis of Computer Information Management System Security
}

\author{
Xiaoling Shi ${ }^{1, a}$, Xiaoping Shi ${ }^{2, b}$, Zhitian Zhang ${ }^{3, c}$ \\ ${ }^{1}$ Changsha Environmental Protection College, Hunan, China \\ ${ }^{2}$ Hunan College of Information, Hunan, China \\ ${ }^{3}$ Hunan Industry Polytechnic, Hunan, China \\ a E-mail: hnzhangzhitian@163.com \\ ${ }^{b}$ E-mail: shixiaoping@mail.hniu.cn \\ c E-mail: shixiaoling@126.com
}

Key word: Computer; Information management system; Security

Abstract: This article takes the computer security management as a breach, from the different angle analysis influence computer information management system security factor, the discussion guards against each kind not to favor the computer information management system security the countermeasure and the measure, guarantees the computer information management system the security order movement.

\section{Computer Information Management System Security of the Content and Its Importance}

The computer information management system, namely in the modern science and technology foundation, the information management system which the network, the computer data processing unifies.The computer information management system security is take the security as a core, through technical methods and so on installment anti-virus software, password authentication, status recognition as well as encryption transmission, the active control computer software and hardware exempts is destroyed deliberately enable the information to have certain secrecy, because not accidentally or the malicious factor has the change, the revelation or the destruction, guarantees the operating system the security.Under network information environment, the people had the enormous dependence to the information system, the request have been more and more high, any security hidden danger, all possibly caused the entire information system breakdown. Therefore the enhancement information management system safe guard measure, regarding the comprehensive promotion informationization construction level, speeds up the social economy development, has the vital practical significance and the profound historical significance.

\section{Influence Restriction Computer Information Management System Security Factor}

Computer information management system for security problems, partly because of the computer information management system of design specification is not reasonable enough scientific and systematic design procedures and strict, causing computer system vulnerabilities followed due to lack of features, related device configuration is complete, comprehensive enough, resulting in unstable system operation and security. Insofar as the present situation is concerned, threatening the safety of computer information management system are main factors in the following areas: 


\section{the Invasion Computer Information Management System.}

From the safety of computer information management system of view, some hackers use illegal procedure, the invasion of computer information management system, the computer information management system of China's government departments some hacker attack, making some system is damaged, the site and home page is modified, the home page is posted some harmful information, attack paralyzed state some of the network system, caused incalculable economic loss and bad social influence.

\section{the Destruction of Computer Information Management Systems.}

Some hackers use or production of illegal procedure, illegal computer intrusion State organs and units of computer networks, and computer network information about the data file tampering, modification and change .

\section{the Destruction of the Computer System Data and Programs.}

Some hackers use network vulnerabilities, illegal invasion computer network system, and through the remote control computer system, some important configuration files from the computer system, network data, homepage information, E-mail, or even the BBS system data such as delete all, inevitably cause computer network system paralyzed, unable to function properly, and the deleted some important documents can't recover.

\section{Dissemination of Computer Viruses and Other Destructive Programs.}

A number of people on the Internet and download hacking programs, use your own or in your computer, and a computer network the junction on the A virus program to scan for and attack the computer network system, with the result that the attack of the computer system slows down, the phone freezes, does not operate normally, and even damage them. From a management and technical factors to look at, and inefficient management is the main reason, however, does not have a firewall set up the computer network system security problems scale is relatively large.

\section{the Safety of Computer Information Management System of Countermeasures}

\section{Enhancement Security System Construction.}

Strictly according to the national law laws and regulations and the correlation secrecy system, establishes the perfect engine room entrance guard system, strengthens based on the computer information security visit jurisdiction control, the standard computer run environment; Formulates effective guard measures and so on the security policy, safety work service, implements the system software the test appraisal and the risk assessment, eliminates the risk hidden danger is examining the link; Regularly to computer conditions and so on information management system movement environment, working condition, owner carries on the inspection, carries on the test and the maintenance according to the system request to the system, guarantees the computer information management system the safe operation.

\section{Constructing Safety Protection System.}

Computer information management system should use the password authentication method, authentication, firewall, intrusion detection, security encryption, PKI certification, effectively protected from hackers, promote the use of safe operation of encryption technology.

\section{(a)Password Authentication.}

The password authentication is maintains the computer system safety handling to be widespread, the method relatively simple one way.Usually, the password is the user and the system agreement code, the system should establish password the change cycle, the due reminder change. When use, only then the user correctly inputs the password which establishes, only then enters the system normal work.. 


\section{(b)Authentication.}

Identity authentication is an effective method in computer security protection system identification of operator legal status, it is the information system first pass, will identify the unauthorized users from primary isolation, in-depth protection of system. The identity authentication technology commonly used include the intelligent IC card, static password, dynamic password card, USB KEY and biological recognition technology.

\section{(c)the Application of Firewall and Anti Virus.}

Firewall is a barrier between the internal and external network, the network security management has a crucial role. Strengthen the use of filtering, and in accordance with the rules to implement the control agent, mutual visits between inner and outer net. About firewall software, need to periodically update, at the same time scanning loopholes, ensure the effectiveness of the firewall. Anti virus software is not a panacea, but also hidden safety problems, but often to optimize its management can effectively reduce the chance of virus attack. At the same time, layers of security in the network, but also can improve the security of information.

\section{(d)Intrusion Detection.}

Intrusion detection is a computer system of the second exit after the firewall, is the core of the information system dynamic security technology. It can be the real-time detection of information system, and which can identify malicious behavior of intruders and fast response. Intrusion detection. Intrusion detection is a computer system of the second exit after the firewall, is the core of the information system dynamic security technology. It can be the real-time detection of information system, and which can identify malicious behavior of intruders and fast response.

\section{(e)Security Encryption Technology.}

In order to prevent information intercepted, and even destroyed, it must to be encrypted, such not only can ensure the information security, but also can keep its effectiveness. Data encryption method has a lot of, the research on this subject focus on how to improve the password strength. Data encryption is a complex process, usually through encryption devices and key, convert raw data into ciphertext. In the process of using data must be decrypted, the plaintext cipher reduction into identifiable. Encryption technology to appear before the invention of the computer technology, and enduring, is more widely used in the network information management.

\section{(f) PKI Certification.}

PKI refers to the user's private key confidentiality features to achieve the authentication process, and then using a digital certificate to the legitimate user-provided evidence that establishing mapping relationship. In fact, this is a mandatory certification system, this method has been in the computer information management system, many areas have been able to apply, the effect is very good.

\section{Conclusions}

With the rapid development of computer technology, network technology and information technology, computer information management system in people's learning, life and work have been widely used, the security problem of computer information management system ignited can not be ignored.

\section{Acknowledgment}

The Project of Hunan Province's Education Department (The Research of Three-dimensional Garage Device Based on PLC Control)Project Code: 14C0371 


\section{References:}

[1]Zhu is on. The computer network information management and its security policies ( $\mathrm{J}$ ' computer knowledge and technology, 2012 (18)

[2]Track trading Lin. Talk about the school computer information system security management measures (J. Scientific and Technological Information Development and the economy, 2013 (35)

[3] Zhu ping a computer network security against the J. talents, 2013 (03)

\section{Author synopsis}

Xiaoling Shi, female, (1979-) Changsha, Hunan province, Computer Engineering Dept of Changsha Environmental Protection College, Hunan The research direction is Computer Application.

Communication address: Computer Engineering Dept, Changsha Environmental Protection Zip Code: 410004 College, Jing Gui Road, Yuhua District, Changsha, Hunan province.

Mailbox: shixiaoling@126.com 